\title{
ALEJANDRO ZOHN'S MATHEMATICAL DESIGN PROCESS, APPROACH THROUGH THREE-DIMENSIONAL ANALYSIS
}

\author{
ALFRED ESTELLER AGUSTII ${ }^{1}$, ISAMAR A. HERRERA PIÑUELAS ${ }^{1} \&$ ADOLFO VIGIL DE INSAUSTI $^{2}$ \\ ${ }^{1}$ Universidad del Valle de Atemajac, México \\ ${ }^{2}$ Universitat Politècnica de València, Spain
}

\begin{abstract}
Alejandro Zohn (1930-2000) was one of the most important architects in the second half of 20th century in Guadalajara, Jalisco. Their work in public space is linked to the most important spaces in the city, although the studies about him have left most of his process and architectural and spatial comprehension. With well-known teachers and references like Mathias Goeritz, Félix Candela or Eduardo Torroja, Alejandro developed a design process based on arithmetic compositions using geometric pure volumes, in most of the cases in concrete. Alejandro Zohn's commitment with mathematical and geometric purity relates him with nature and its rules, also depending on mathematics and fractal growth, what leads his designs to a good public appreciation although the state of conservation is quite disturbing in some of the cases due to administration neglect.

In the case of the works for public spaces studied in this paper, Alejandro Zohn generated a fractal growth in order to balance the volumes, weights and dimensions, with the use of hyperbolic paraboloid to lead the structural stress of the demanding forms to the floor with the highest lightness possible

In order to achieve a full vision of this growth and balance, this work focuses in showing the volumes used in the composition transforming them from the two usual dimension of floor and elevation to three-dimensional volumes, showing the conceptual complexity of this two apparently simple shapes. Keywords: fractal growth, functional structures, geometry, hyperbolic paraboloids, monumentalism, nature-related forms
\end{abstract}

\section{INTRODUCTION}

On the second third of 20th century in Guadalajara, Mexico, architecture production experienced an explosion as it was never seen before, not only about the amount of production, with the uncontrolled expansion of the city, but about its quality and important projects which nowadays are still a referent in the city.

Well-known architects like Luis Barragán, Mathias Goeritz or Ignacio Díaz Morales can be studied, in order to understand nowadays architecture references in the city. But in order to understand the public spaces of the city, and how they arrived to achieve their moment of splendour and later downfall is needed to analyse the figure and works of Alejandro Zohn (1930-2000) [1]. As he was the architect who defined successfully most of the big public spaces such as Agua Azul Park, López Mateos sport complex, Liberty Market, 14th February sport complex and park, or the pedestrian bridges in the Colomos Park, which still keep part of their preceding greatness in the city.

\section{ALEJANDRO ZOHN'S CAREER}

\subsection{Childhood and studies}

Although Alejandro Zohn Rosenthal was born in Austria, on 1930, he moved to Mexico in his childhood, and settled with his mother, who was chemist, and his father, who was accountant, in the town of Tlaquepaque. With a childhood marked by science and mathematics, he 
studied civil engineering in the Universidad de Guadalajara, but when architecture studies were available in the same university, he decided to study both at the same time, ending Civil Engineering degree on 1955 [2] and the architecture degree, according to the yearbook of the University of Guadalajara [3] in 1959. Becoming this double formation in the foundation of its later architecture and spatial comprehension both in buildings and public space projects.

In Alejandro Zohn's double formation stand out Dr. Marian Goeritz [4] her married name, real Marianne Gast, photographer and writer [5], architect Jaime Castiello Camarena [6] influenced by the modern movement, architect Ignacio Díaz Morales [7] precursor of regionalist architecture [8], Prof. Domingo Lobato [9], composer, organist and teacher [10], Ing. Francisco González Rojo [11] writer, film scriptwriter and ethnologist [12], Architect Eric Coufal [13] work inspired by the Mexican tradition, specifically in crafts, Dr. Manuel Herrero Morales [14] Mathematician professor from Spain [15], Mr. José Arriola Adame [16] and Dr. Mathias Goeritz [17] architect, sculptor, painter, poet and art historian [18], this one, played a key role from the beginning of Zohn's training, being the reason why he decided to enter the architectural career: 'I kept studying engineering, and at that time a series of people came to what was the school of architecture, among them Mathias Goeritz. I met him casually on one of the visits, and since I had some time between engineering classes, I got into some of his classes and I liked them a lot. I think it was because of Mathias that I got into architecture' [19].

Special consideration in Alejandro Zohn's education was the Spanish architect Félix Candela, as a usual guest teacher in Universidad de Guadalajara [20] after his exile after Spanish civil war [21], even more when the two pieces analysed in this investigation are shell structures in concrete, in which area Félix Candela is the most recognized pioneer.

\subsection{Alejandro Zohn design bases}

In the collective consciousness of Guadalajara, Alejandro Zohn works have a special place, even unknowing to the author who create them, as the most iconic public spaces in the city growth in the second half of past century have their footprint. For architects, urban and history interested Alejandro Zohn is an essential figure for understanding nowadays Guadalajara. 'Zohn represents, maybe as any other member of his generation - and all the other generations graduated from Diaz Morales' school (...), a living and literal synthesis of the two main lines that embody the best architecture that has ever been built in this region. On one side, the rigor of the number and the method, of the economy and the efficiency. On the other, the flight of imagination and the cultural background of a rich and contradictory past' [22].

These two academic lines of the university, strengthen in Alejandro Zohn by the previously explained duplicity of studies, make the base for all his works, where the use of an extremely precise mathematic definition of the projects with the adoption of natural references, also defined by mathematics, lead the configuration and expressivity of the architectural object.

Focusing on the projects for public spaces, the answer to the project incorporates the public dimension, and the use of paraboloid, hyperbolic paraboloid and other mathematic figures allow Alejandro Zohn to create the most expressive shapes and spaces in the moment when this kind of geometries were in doubt about their functionality.

\section{SELECTED WORKS}

For the analyses in this work, the two of the most important pieces in public space made by Alejandro Zohn were chosen, in first place the Acoustic shell inside the Agua Azul Park, 
where he developed some other interesting pieces like the pedestrian bridge which runs above an avenue. And, in second place, the main entrance of a whole project of him, the López Mateos Sport Complex.

Both pieces, the most relevant parts of whole projects, have the astonishing presence that Alejandro Zohn choose to the most iconic places of the projects. In first place, and outdoor auditorium, where the mathematical form of hyperbolic paraboloid is used, in addition of structural lightness and material efficiency, as the responsible of spreading the sound of the different performances in the most appropriate way. In the case of the entrance to the Sports Complex, the shape is far more intricate, as Alejandro Zohn combines precisely five main hyperbolic paraboloids in one unique piece with the shape of a cross.

Also, in these two elements, the commitment of Alejandro Zohn in all his curve shaped works with the mathematics behind the geometry is remarkable, as he does not modifies the geometry of the hyperbolic paraboloid in any sense, as well as he delimitates all the shapes with straight lines, which is what hyperbolic paraboloid is generated from.

\subsection{Acoustic shell in Agua Azul Park, Guadalajara, Jalisco}

In 1959, Alejandro Zohn is entrusted to design an acoustic shell for the most important urban space on that time, while he was still a graduate from his civil engineering studies and still had not graduated in his architecture studies [23].

Geometrically, the shell is the central portion of the hyperbolic paraboloid Alejandro Zohn uses to distribute the sound far and wide on the audience pit. In this case, while the hyperbolic

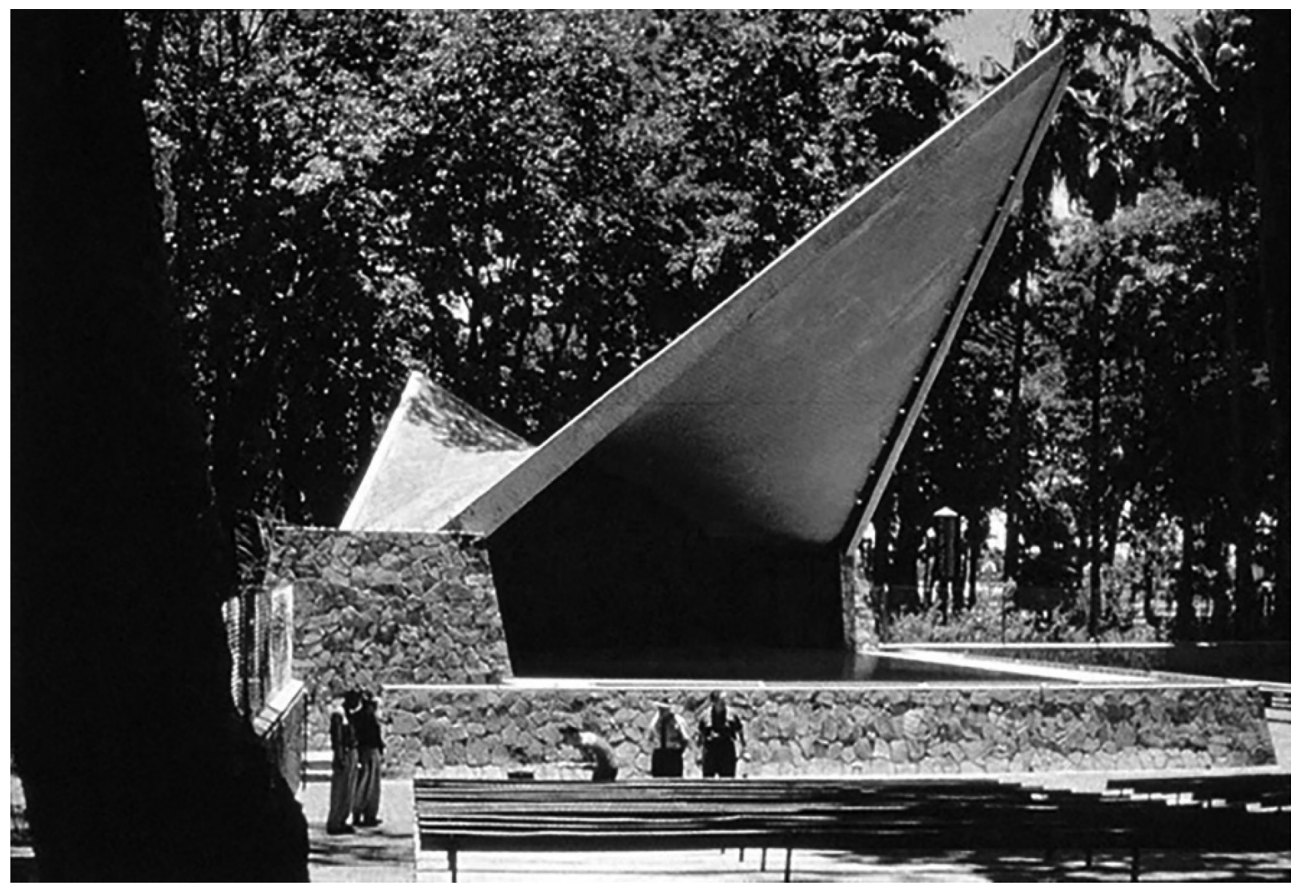

Figure 1: Acoustic shell in Agua Azul Park (Zohn's archive). 
paraboloid is used to take advantage of its internal structural strength, the length of the two elevated corners is different, generating the centre of mass centre is displaced to the acting area. This imbalance is solved by Alejandro Zohn with the wide stone pilasters on both sides, gathering the centre of mass position within their area.

\subsection{Main access in López Mateos sport complex, Guadalajara, Jalisco}

In the same year, Alejandro Zohn designs the López Mateos sport complex, in which settles for the entrance an eight corners element joining five different hyperbolic paraboloids, one in the centre and four for the wings with four more paraboloids for the junction. In addition, for reinforcing forces distribution between the two biggest wings and reducing the high stress generated in the junctions of the paraboloids, Alejandro Zohn generates a second layer of hyperbolic paraboloids above the first one, contributing to the momentum of the long cantilevers generated.

Thus, in this more complex piece, Alejandro Zohn shows his ability to compensate the weights in four directions from the centre paraboloid, while using three different lengths and heights on the wings. Being possible through the use of the pure mathematics shapes and graphics for the perfect union of the consecutive paraboloids.

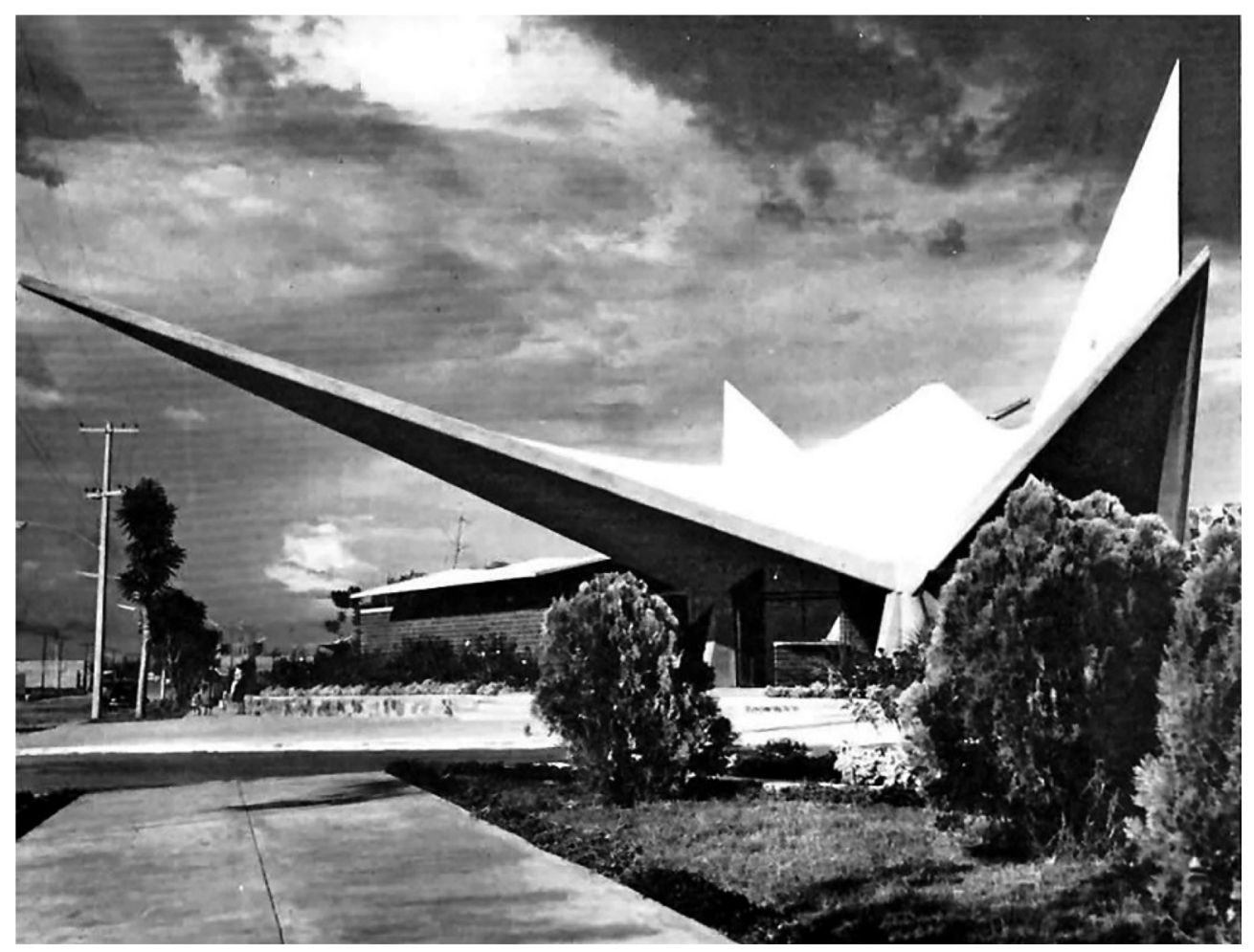

Figure 2: Main access in López Mateos sports complex (Zohn's archive). 


\section{METHODOLOGY}

The relationship between geometry, nature and public space appreciation is the connectors for the mathematical geometry used by Alejandro Zohn. With the aim to create impressive shapes and forms that seem to challenge the laws of physics, he incorporated the forms of nature into his designs, positioning him as an advanced to nowadays used concepts of biophilia and fractal nature inspired designs. The junction of this valued concepts, where building environment is understood as an extension of the humans and, therefore, more appreciated in a subconscious level [25] and linked to natural processes carried out in the basic, cellular, and chemical nature [26] seems to be related to the esteem by citizenship.

The methodology applied is based on geometry and mathematics using a three-dimensional analysis of the golden ratio through a three-dimensional modelling of the cubes which define Alejandro Zohn's projects. And, contrasting it with the results of public appreciation of them in public space according to the results of a survey carried out in the city of Guadalajara [24] shows public appreciation of the projects from Alejandro Zohn analysed in the current study in comparison with other projects of similar characteristics where other examples do not present this kind of sensitivity to nature. Particularly, in the results to the question of which shape seems more attractive to surveyed people, as can be seen in Fig. 3, where Alejandro Zohn works are coloured blue. This survey was answered by 117 people in order to fulfil a 95\% trust and 15\% margin of error with the population established around the two parks where the urban elements selected are 41,455.

Alejandro Zohn's acoustic design is preferred with a $33.3 \%$, but close to other two options. It can be interpreted as most of the shells have designs that can be appreciated by the society. Nevertheless is important to notice than comparing with the next two options, Zohn's construction is by far the one in worst maintenance condition, what must lead to a thought about the care of local architecture referents in our cities.

For the next element studied, the impressiveness of the form explained of Zohn's design for Sport Complex' main access in López Mateos is shown with the biggest difference in voting, as other entrances for parks in the city have more sober and rectangular designs, what differences it notoriously from the others, even being in one of the least glamourous areas of the city, while in other photographs were entrances of more appreciated, more cared and visited parks, located in wealthier neighbourhoods.

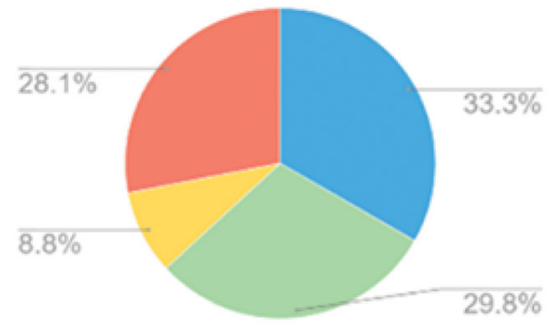

Question 1. Acoustic cell preferences.

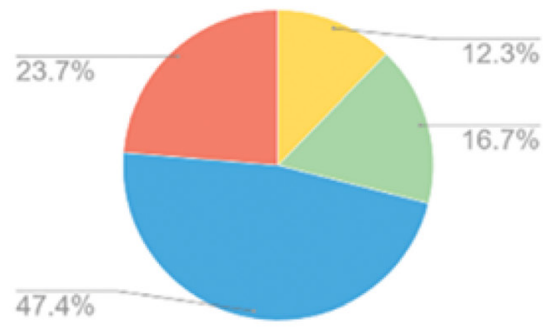

Question 2. Park access preferences.

Figure 3: Survey results to question 'Which shape is more attractive to you?'. 


\section{GEOMETRIC ANALYSIS, TWO- AND THREE-DIMENSIONAL}

In order to understand the geometry of buildings, specially related to analysis of geometry linked to golden ratio, these studies have been made in floor and elevation plans, where golden ratio is drawn on the plan showing the harmony of the designs and their internal relationships.

Nevertheless, nowadays way of working, in which designs are predominantly developed in three dimensions through the whole process of designing, from the general conception to the details of engineering thanks to technological advances brings other questions to be solved.

The one searched to be attended in this paper is how far the two-dimensional geometric analysis have left aside the real perception of the architectural object by the users, as their inherent three-dimensional reality can modify the recognition of proportions. So that realizing that both analysis, floor and elevation, need to work together specially in those cases where the elements studied are far from being flat, as the usual analysis of flat facades of a church front. In these cases, the visual distortion of the observer added to the dimensions and different planes between the different volumetric elements generates the doubt of the convenient appreciation of the proportion understood and obtained in two-dimensional analysis.

For this reason, in the present paper, a three-dimensional analysis is made for two pieces selected of Alejandro Zohn, developing a previous work of two-dimensional analysis [24] based on golden ratio ( $\varphi=1: 1.61803 \ldots$ ) with the result of Figs. 4-7, respectively. Evolving the comprehension of Alejandro Zohn's pieces with the aggregation of proportions in a unique three-dimensional model.
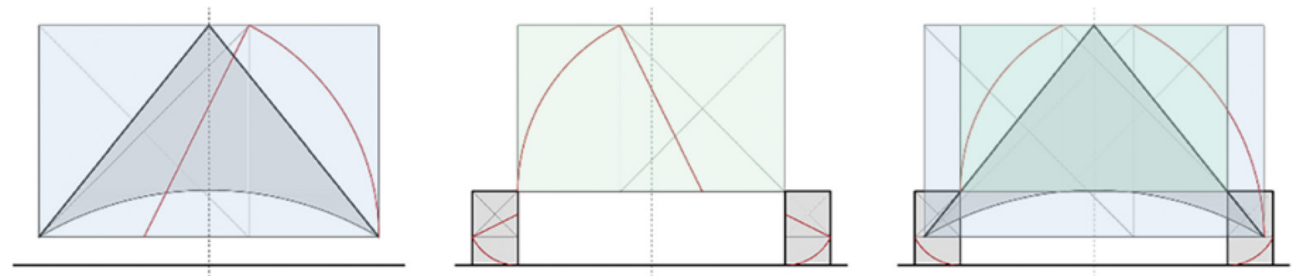

Figure 4: Acoustic shell, frontal view, geometric analysis.
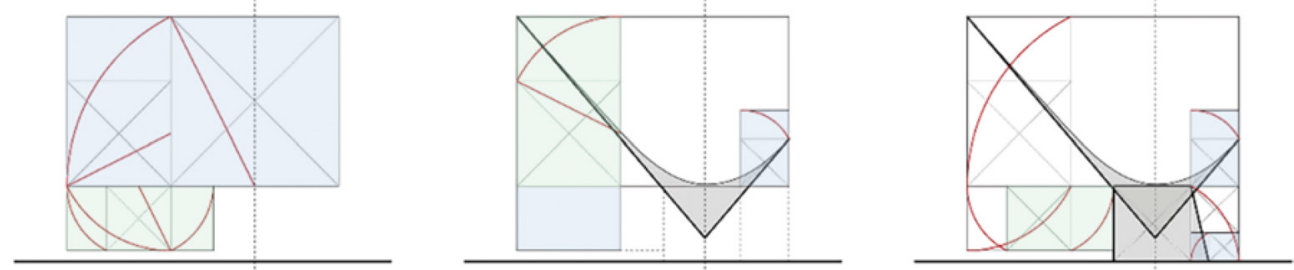

Figure 5: Acoustic shell, side view, geometric analysis.
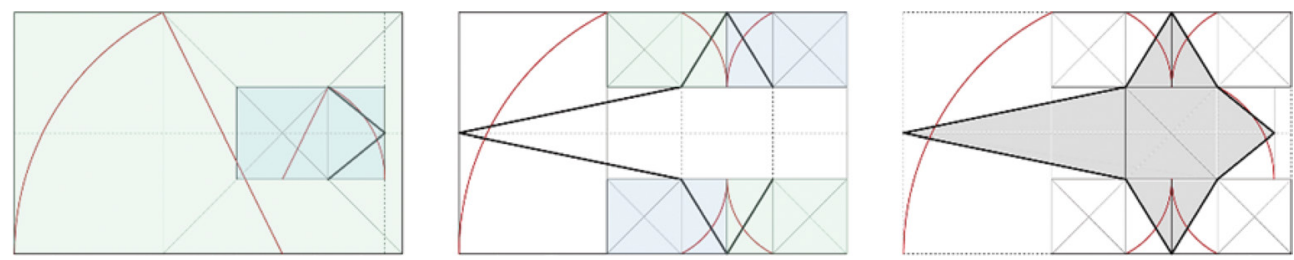

Figure 6: Access, floorplan, geometric analysis. 

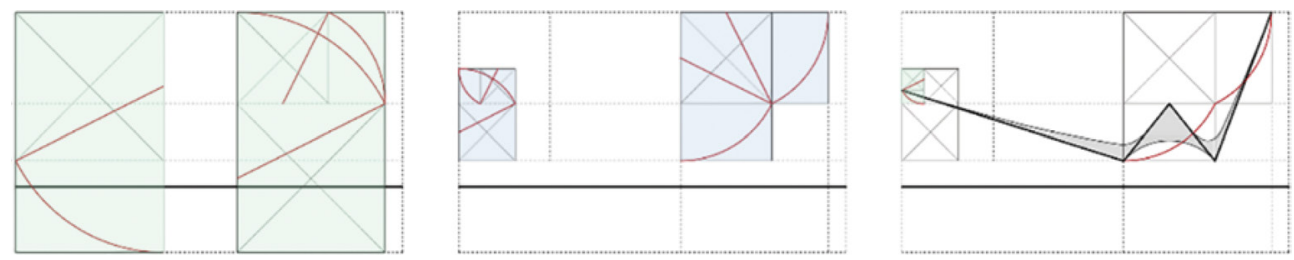

Figure 7: Access, sideview, geometric analysis.

\section{THREE-DIMENSIONAL UNDERSTANDING OF ALEJANDRO ZOHN'S WORKS}

The starting point in the analysis in both cases is the biggest cuboid related to the hyperbolic paraboloid concrete shell with dimensions of 1:1: $\phi$ (height:length:depth). From which succeeding reductions point out the position of each point that confines the hyperbolic paraboloid.

\subsection{Acoustic shell in Agua Azul Park, Guadalajara, Jalisco}

In the beginning for the analysis of the acoustic shell, composition starts with a basic orthohedron with the golden ratio proportion in length, the same direction as the frontal cantilever, as can be seen in the elevation analysis, Fig. 5. This initial cuboid defines the top corner of the shell, while with two golden ratio divisions the main horizontal square for the shell is delimited and the smallest cube will be the beginning for the definition of the height and position for pilasters.

From the smallest cube, located in front corners, an extension is grown by golden ratio, from there a new division and extension marks off the position for the pilasters.

Therefore, the next golden ratio for pilasters is defined as well as its position, also determined by the second golden ratio division of itself. In upper direction, the same cuboid of the pilasters but inside the initial orthohedron positions the exact point for the top corner of the shell in the posterior wing.

Also, in figure 10 can be seen that, although in two-dimensional interpretation the frontal proportion of the main shell generates and own golden ratio rectangle, when working with the three dimensions together, the exact point of the low corner of the shell can be found with the third split developed in the cuboid related to define the two stone pilasters on the sides. What is far more exact and offers us a new understanding not only about the proportions between pieces that could be seen more unconnected in two dimensions, but about the relation of these corners with the pilasters and the centre of mass located in the area structurally controlled by the pilasters. What shows us about the real distribution of forces between the shell and pilasters, and the relation of the direction of the shell in its lower edge and the tilt of the exterior edge of the pilasters, which is also defined by the golden ratio.

In sum, the correlative evolution of the cuboids from an initial simple form shows in this project how the dimensions are related between and with a whole, obtaining the aesthetic, functional and structural balance pursued and, as said, appreciated by the observers.

6.2 Main access in López Mateos sport complex, Guadalajara, Jalisco

The case of the entrance to López Mateo's Sports Complex the shape is fully composed inside a main orthohedron defined by golden ratio in both long sides and a square face. 

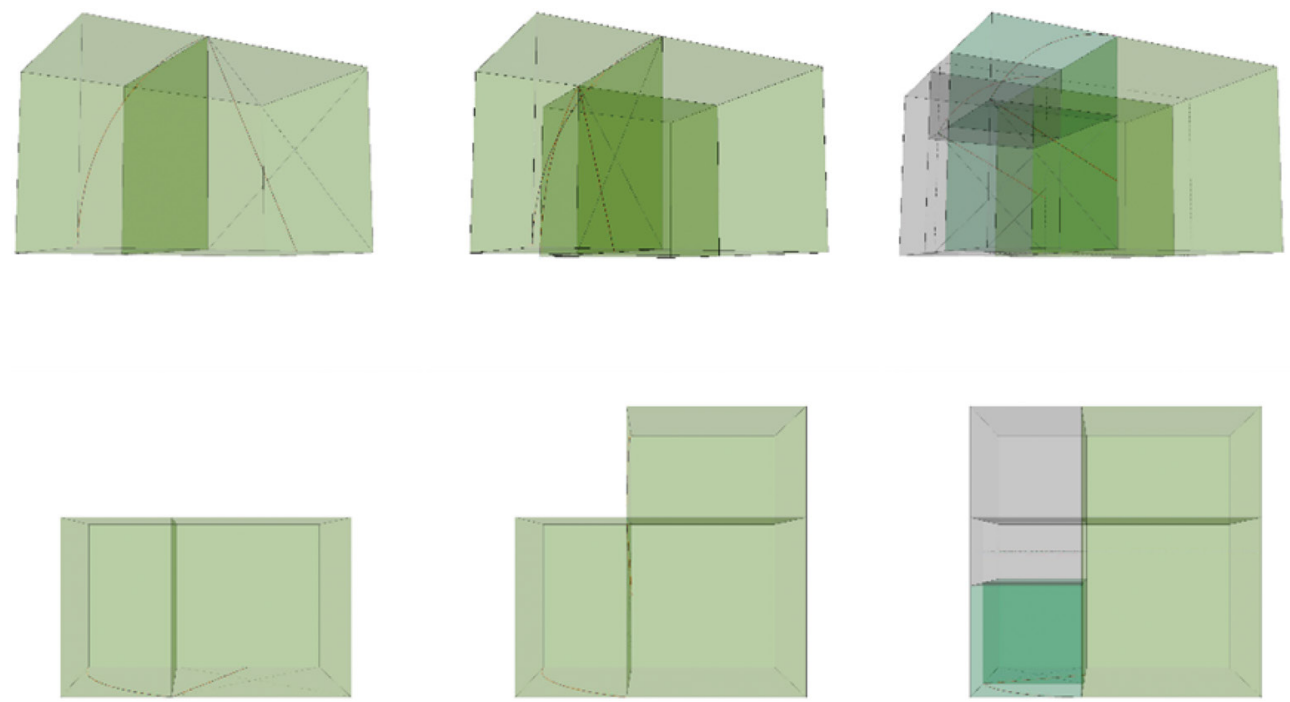

Figure 8: Initial three golden ratio evolutions for the acoustic shell.
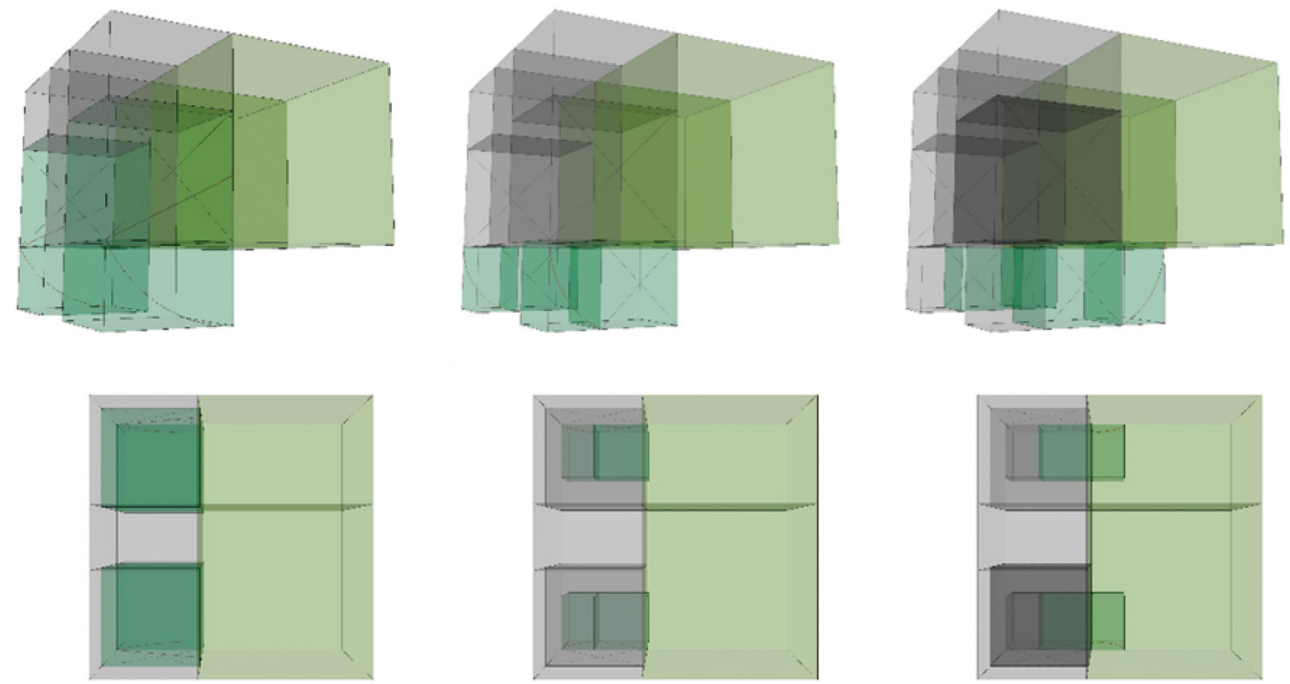

Figure 9: Halfway golden ratio evolutions for the acoustic shell.

Growth in its evolution is developed along four different geometric series of Fibonacci's section surrounding a squared central space, where the entrance is located. This central space gathers the different forces from the four directions locating the centre of mass and conducting the forces to four only supports under the four central delimiting points of the group of hyperbolic paraboloids. This way the whole piece is balanced structural and aesthetically, as well as functionally. 

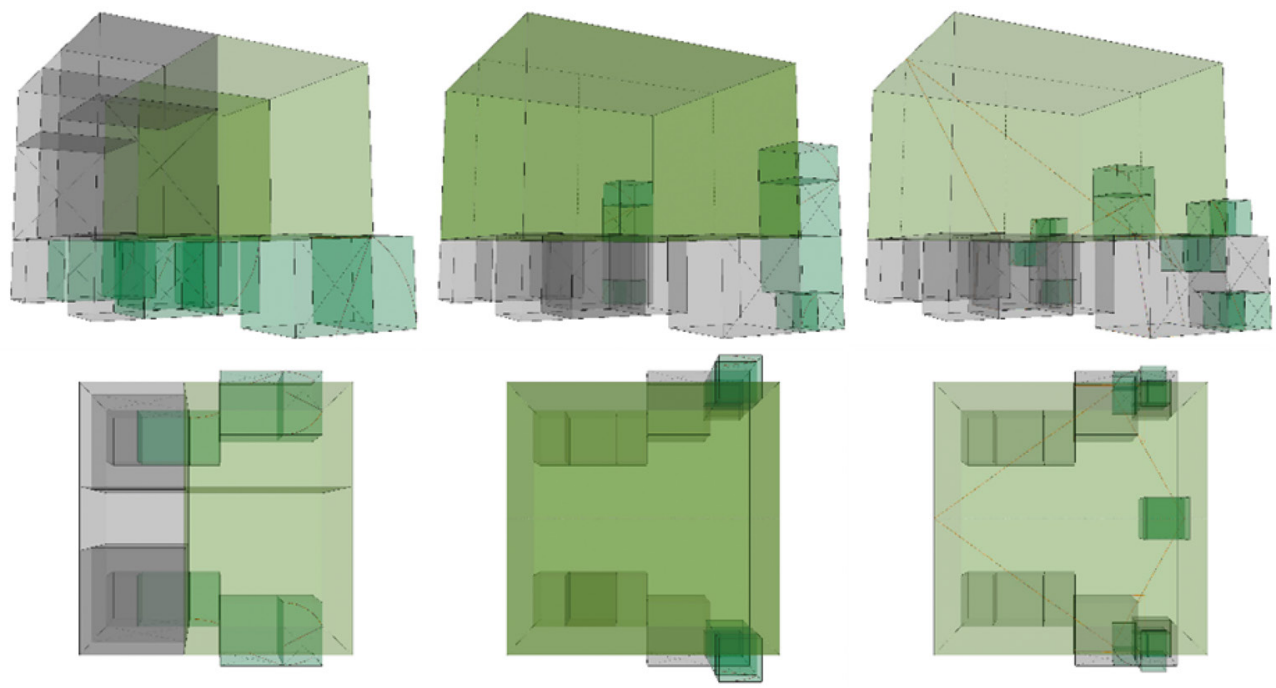

Figure 10: Final golden ratio evolutions for the acoustic shell.

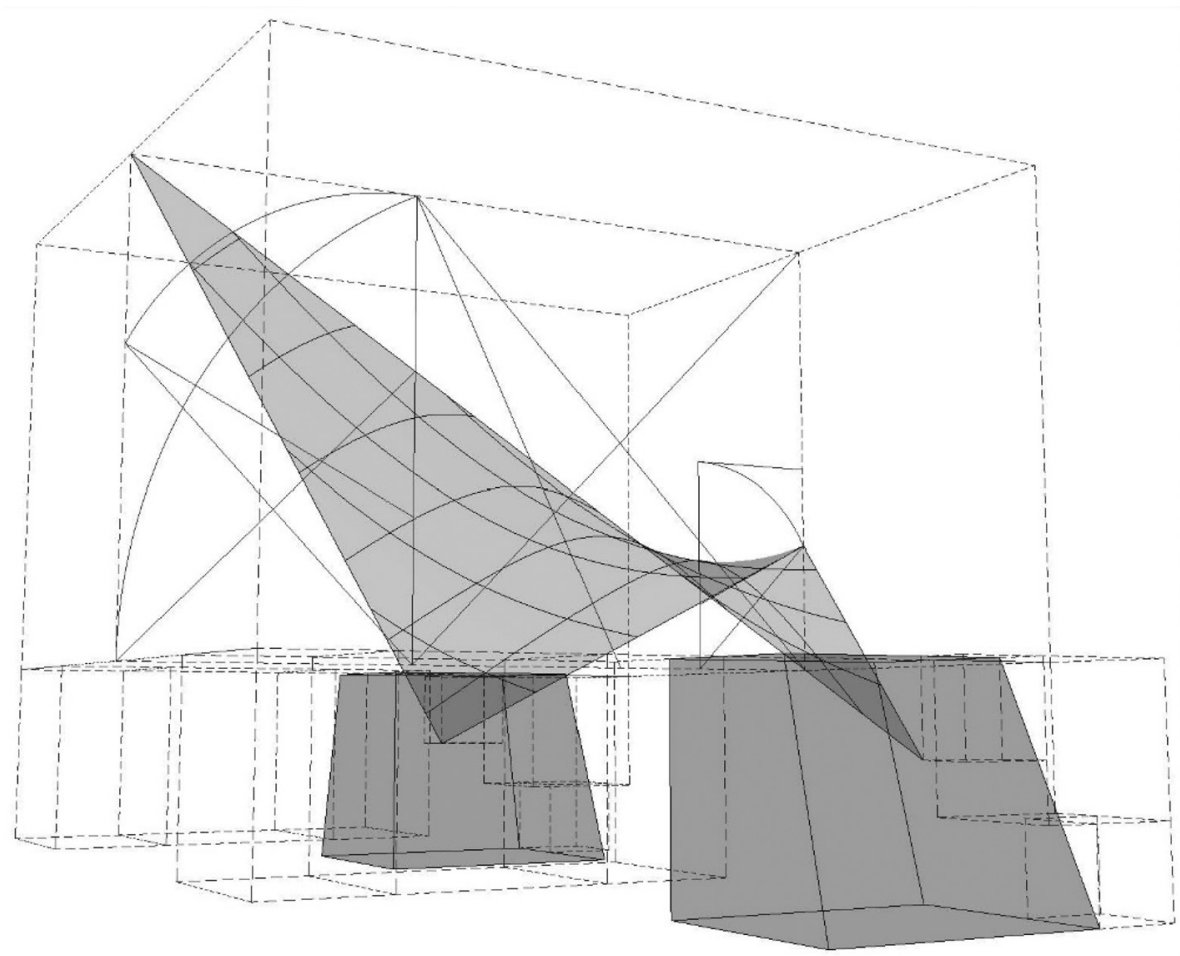

Figure 11: Summary three-dimensional golden ratio configuration for the acoustic shell. 
Initially, the big golden rated cuboid is divided three times along the edges of the main cuboid by golden ratio in order to obtain the dimension of the central cube, from where the four wings of the shape will expand. This case has more complex evolution than the acoustic shell, therefore Figs. 12-15 are used to display the most representative moments in the evolution of the analysis, so some of the steps do not appear because of space saving reasons.

From the golden ratio cuboids around the central space, as can be seen in lower right position of figure 12, extracting the cube and expanding by golden ratio horizontally, both lateral wings are defined in their three points, as shown in first pair of images in Fig. 13. Coming back to the main central cuboid over the entrance, expanding it also horizontally top corner is in the centre
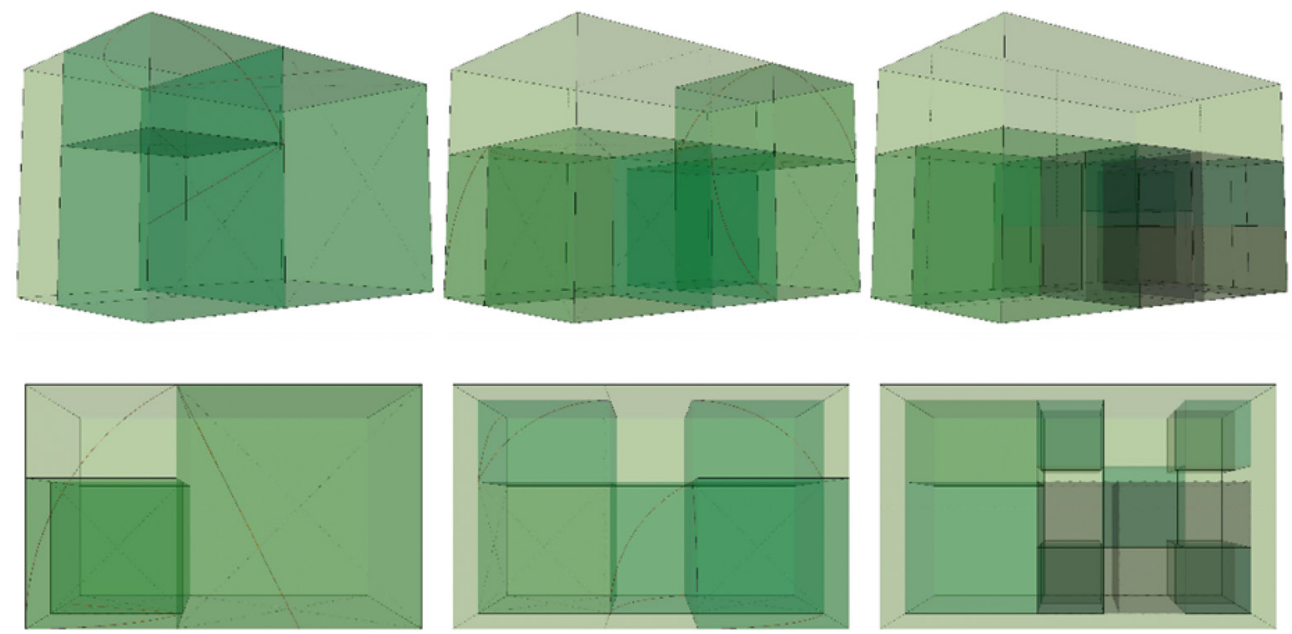

Figure 12: Initial selection of golden ratio evolutions for the access to sport complex.
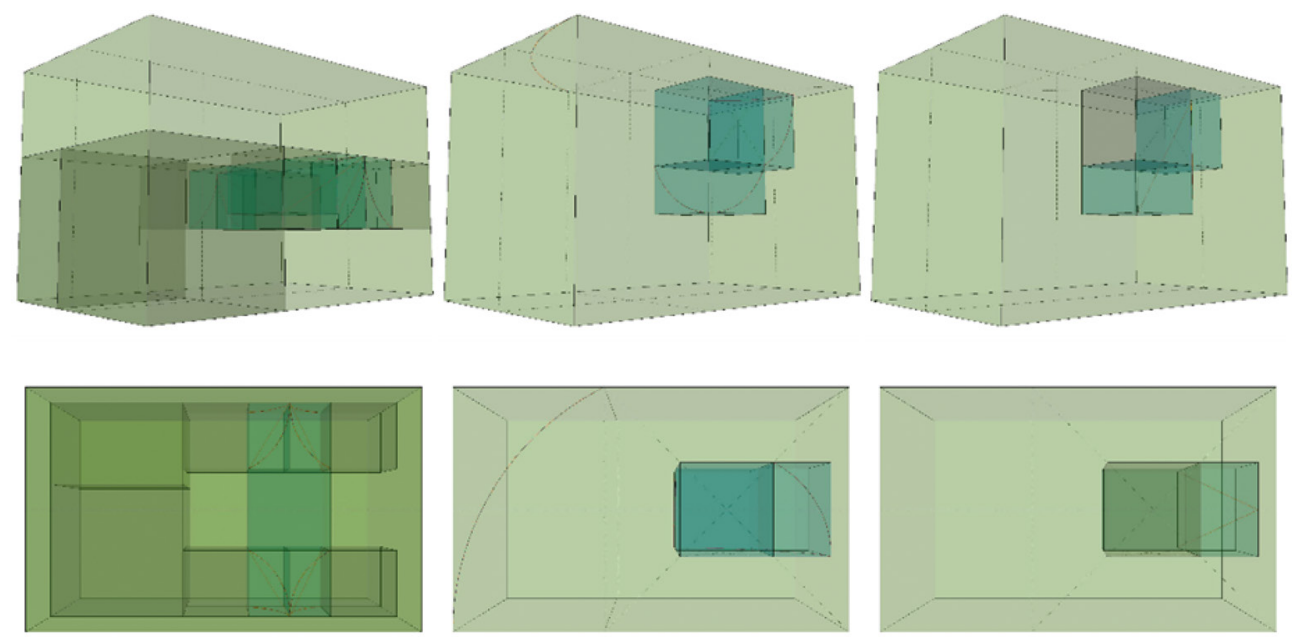

Figure 13: Second selection of golden ratio evolutions for the access to sport complex. 

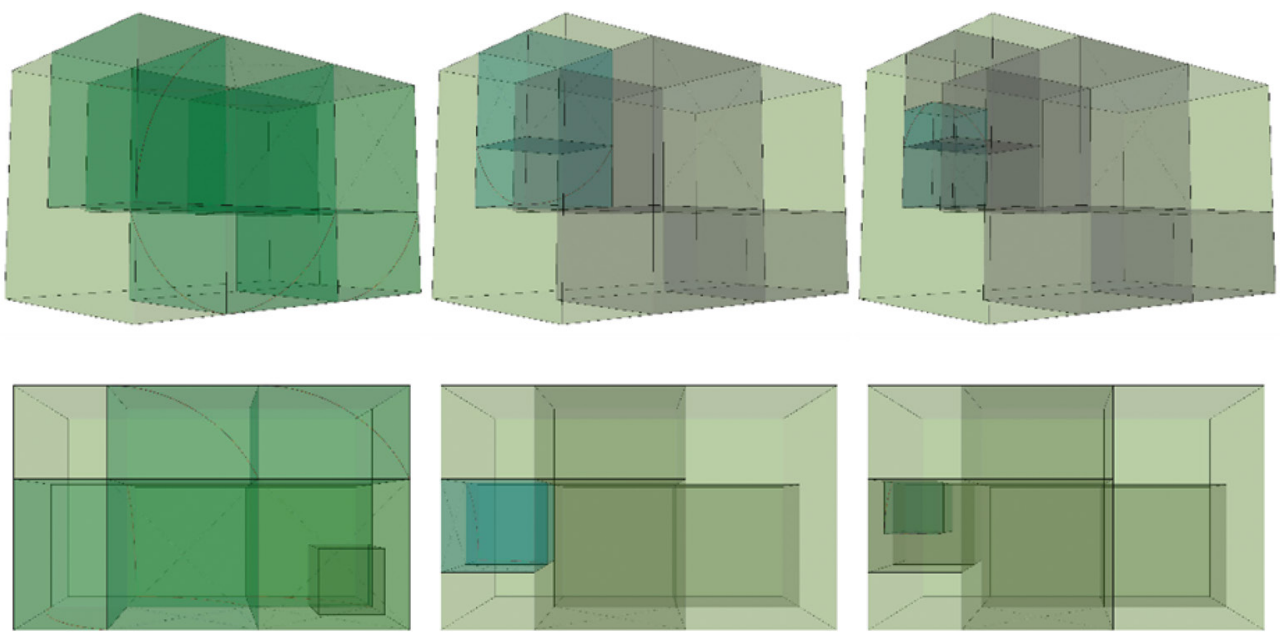

Figure 14: Third selection of golden ratio evolutions for the access to sport complex.
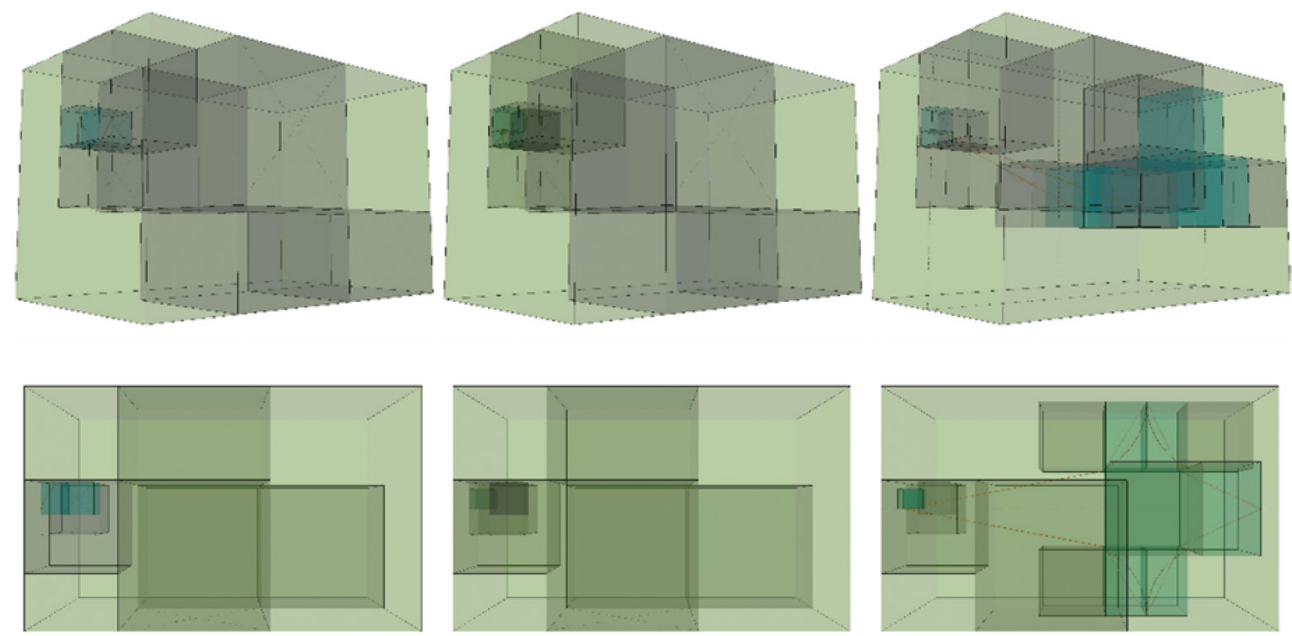

Figure 15: Final selection of golden ratio evolutions for the access to sport complex.

of the horizontal golden rated volume while on the vertical also golden rated volume are located in the two lower corners.

The final dot left is the one which is more representative in the structural element, as the final point of the cantilever above the sidewalk. To achieve its position, the first vertical division of the initial cuboid is needed to go back, as seen in the first pair of images in Fig. 14. Then, in its horizontal golden ratio, three internal and successive golden ratio evolutions set the height of the last point in the cantilever.

In sum, an important amount of iterations have been developed for this case, accordingly with the more complex configuration of the element, where gravitational forces in four directions are guided to four central points which connects the light shape with the floor. 


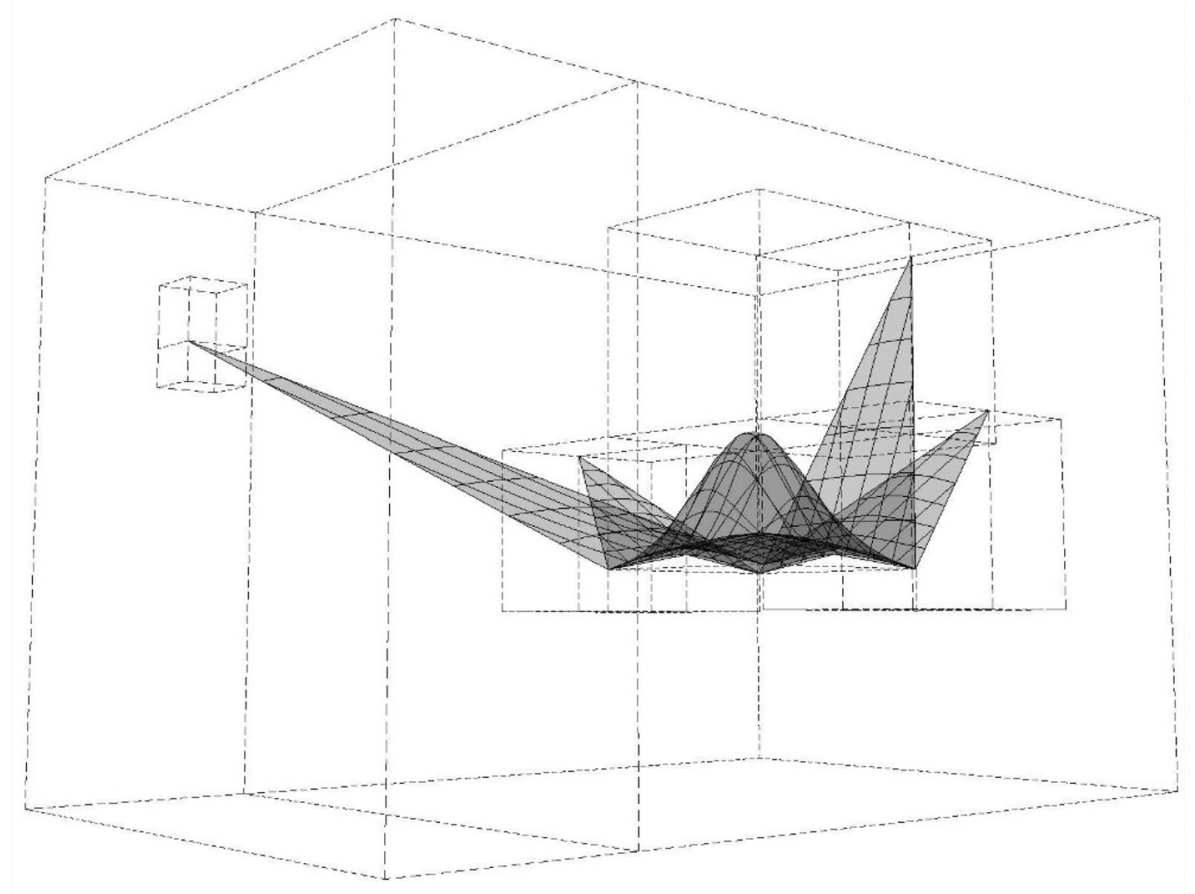

Figure 16: Highlighted three-dimensional golden ratio volumes for the definition of the access to sport complex.

\section{CONCLUSIONS}

After the three-dimensional analysis of the two pieces of Alejandro Zohn, and regarding the previous results developed in floor and elevation plan, it is important to accept the limitations of two-dimensional examination when studying volumetric pieces proportions, as the dissertation of volumetric pieces has made possible to spot several new correlations in both examples. From which results can be understood far more complex mathematical and perceptual associations can be found when working with models and volumetric geometries.

This reflexion also opens the path to a further revision of many analysis performed in two dimensions, not with the intention to expose any potential errors or faults in the investigation, but with the purpose of finding relations and proportions that have remained hidden until now. So, the appreciation and understanding of the buildings can be enriched and design process associated can be reinterpreted.

Having a new approach to understand proportions and volumetric relations, in which pedestrian observers are included as the key point of the three-dimensional understanding is related with how watchers perceive and valuate the interest of built environment. In this way, three-dimensional studies are more suitable to understand how design process should propose the aesthetic of public spaces design and proportions, taking into account for example the distance of the observer, the dimension of the object designed and the complexity of the object. 


\section{REFERENCES}

[1] Enciclopedia histórica y biográfica de la Universidad de Guadalajara, Universidad de Guadalajara, available at: http://enciclopedia.udg.mx/biografias/zohn-rosenthal-alejandro (accessed 19 January 2020).

[2] Universidad de Guadalajara, Enciclopedia histórica y biográfica de la Universidad de Guadalajara, available at: http://enciclopedia.udg.mx/biografias/zohn-rosenthal-alejandro (accessed 19 January 2020).

[3] Universidad de Guadalajara, Facultad de arquitectura 1948-1983. ed. Universidad de Guadalajara, Facultad de Guadalajara: Guadalajara, Jalisco, Mex., p.91, 1983.

[4] Universidad de Guadalajara, Facultad de arquitectura 1948-1983. ed. Universidad de Guadalajara, Facultad de Guadalajara: Guadalajara, Jalisco, Mex., p.84, 1983.

[5] Presentación de Marianne Gast (1910-1958) en el archivo Lafuente, Librería Gil. Premio Nacional Librería Cultural, available at: https://www.libreriagil.com/mariannegast-1910-1958-en-el-archivo-lafuente/ (accessed 25 January 2020)

[6] Universidad de Guadalajara, Facultad de arquitectura 1948-1983. ed. Universidad de Guadalajara, Facultad de Guadalajara: Guadalajara, Jalisco, Mex., p.84, 1983.

[7] Universidad de Guadalajara, Facultad de arquitectura 1948-1983. ed. Universidad de Guadalajara, Facultad de Guadalajara: Guadalajara, Jalisco, Mex., p.84, 1983.

[8] Nostalgia regionalista, El informador, available at: https://www.informador.mx/Suplementos/Nostalgia-regionalista-20121027-0022.html (accessed 25 January 2020)

[9] Universidad de Guadalajara, Facultad de arquitectura 1948-1983. ed. Universidad de Guadalajara, Facultad de Guadalajara: Guadalajara, Jalisco, Mex., p.84, 1983.

[10] Cruz, G., Instituto de Investigaciones históricas, políticas, económicas y sociales, available at: https://institutohistorico.org/domingo-lobato-banales/ (accessed 25 January 2020)

[11] Universidad de Guadalajara, Facultad de arquitectura 1948-1983. ed. Universidad de Guadalajara, Facultad de Guadalajara: Guadalajara, Jalisco, Mex., p.84, 1983.

[12] Ortiz, J., Lifeder, available at: https://www.lifeder.com/francisco-rojas-gonzalez/ (accessed 25 January 2020)

[13] Universidad de Guadalajara, Facultad de arquitectura 1948-1983. ed. Universidad de Guadalajara, Facultad de Guadalajara: Guadalajara, Jalisco, Mex., p.84, 1983.

[14] Universidad de Guadalajara, Facultad de arquitectura 1948-1983. ed. Universidad de Guadalajara, Facultad de Guadalajara: Guadalajara, Jalisco, Mex., p.84, 1983.

[15] Kasis, A., Monografías de arquitectos del siglo XX, vol. 1, Alejandro Zohn. Ingeniería, arquitectura y planeación, ed. Pandora, Guadalajara, Jalisco, México, p.148, 2004.

[16] Universidad de Guadalajara, Facultad de arquitectura 1948-1983. ed. Universidad de Guadalajara, Facultad de Guadalajara: Guadalajara, Jalisco, Mex., p.84, 1983.

[17] Universidad de Guadalajara, Facultad de arquitectura 1948-1983. ed. Universidad de Guadalajara, Facultad de Guadalajara: Guadalajara, Jalisco, Mex., p.84, 1983.

[18] Staff, LJA, available at: https://www.lja.mx/2015/04/solo-si-emociona-la-arquitecturapuede-considerarse-un-arte-mathias-goeritz/ (accessed 25 January 2020).

[19] González, F., Mathias Goeritz en Guadalajara, ed. Universidad de Guadalajara: Guadalajara, Jalisco, México, p. 120, 1991.

[20] HANSKABSCH, Parroquia de San Jerónimo en Zapopan. http://hanskabsch.blogspot. com/2010/01/parroquia-de-san-jeronimo-enzapopan.html (accessed 1 February 2020).

[21] Acción Cultural Española, Felix Candela (eBook), AC/E Online https://www.accioncultural.es/es/publicaciones/felix-candela (accessed 25 February 2020). 
[22] Consejo Nacional para la Cultura y las Artes, Alejandro Zohn. Arquitectura y reflexiones, ed. AGATA: Guadalajara, Jalisco, México, p. 8, 1999.

[23] Rábago, J., Monografías de arquitectos del siglo XX, vol. 20, Alejandro Zohn. Ingeniería, arquitectura y planeación, ed. Pandora: Guadalajara, Jalisco, México, p. 49-59, 2011.

[24] Esteller, A., Herrera, I. A., Vigil, A., 'the influence of mathematical composition for public space in the experience of users. Alejandro Zohn's work' WIT Transactions on the Built Environment, Vol 195, WIT Press, 2020, ISSN 1743-3509.

[25] Griffin, C. An introduction to biophilia and the built environment. RMI Solutions, 20(1), p. 7-11, 2004.

[26] Mandelbrot, B. La geometría fractal de la naturaleza. Tusquets editores, p. 32, 1997. 